\title{
Decoction, infusion and hydroalcoholic extract of Origanum vulgare L.: Different performances regarding bioactivity and phenolic compounds
}

\author{
Natália Martins $^{\mathrm{a}, \mathrm{b}}$, Lillian Barros ${ }^{\mathrm{a}, *}$, Celestino Santos-Buelga ${ }^{\mathrm{c}}$, Mariana Henriques ${ }^{\mathrm{b}}$, Sónia Silva ${ }^{\mathrm{b}}$, \\ Isabel C.F.R. Ferreira ${ }^{a, *}$ \\ a Mountain Research Centre (CIMO), ESA, Polytechnic Institute of Bragança, Campus de Santa Apolónia, Apartado 1172, 5301-855 Bragança, Portugal \\ ${ }^{\mathrm{b}}$ IBB - Institute for Biotechnology and Bioengineering, Centre of Biological Engineering, University of Minho, 4710-057 Braga, Portugal \\ ' GIP-USAL, Faculty of Pharmacy, University of Salamanca, Campus Miguel de Unamuno, 37007 Salamanca, Spain
}

\section{A R T I C L E I N F O}

\section{Article history:}

Received 18 January 2014

Received in revised form 17 February 2014

Accepted 20 February 2014

Available online 28 February 2014

\section{Keywords:}

Origanum vulgare L.

Antioxidant activity

Antimicrobial activity

Phenolic compounds

\begin{abstract}
A B S T R A C T
Bioactivity of oregano methanolic extracts and essential oils is well known. Nonetheless, reports using aqueous extracts are scarce, mainly decoction or infusion preparations used for therapeutic applications. Herein, the antioxidant and antibacterial activities, and phenolic compounds of the infusion, decoction and hydroalcoholic extract of oregano were evaluated and compared. The antioxidant activity is related with phenolic compounds, mostly flavonoids, since decoction presented the highest concentration of flavonoids and total phenolic compounds, followed by infusion and hydroalcoholic extract. The samples were effective against gram-negative and gram-positive bacteria. It is important to address that the hydroalcoholic extract showed the highest efficacy against Escherichia coli. This study demonstrates that the decoction could be used for antioxidant purposes, while the hydroalcoholic extract could be incorporated in formulations for antimicrobial features. Moreover, the use of infusion/decoction can avoid the toxic effects showed by oregano essential oil, widely reported for its antioxidant and antimicrobial properties.
\end{abstract} (C) 2014 Elsevier Ltd. All rights reserved.

\section{Introduction}

Plants are used since ancient times by primitive societies due to therapeutic and psychotherapeutic benefits, among other healing properties. In recent years, it has been observed an increasing interest for biological properties of medicinal plants, in order to identify and evaluate their therapeutic potential, and also to identify the major bioactive compounds and possible synergisms (Albano \& Miguel, 2011; Bakkali, Averbeck, Averbeck, \& Idaomar, 2008).

Origanum vulgare L. (oregano) is an herbaceous, perennial and very tough plant, belonging to the Lamiaceae (lipped) family. It is used, since ancient times, for medicinal purposes and, in particular, the antioxidant properties of 0 . vulgare methanolic extract (Barros, Heleno, Carvalho, \& Ferreira, 2010; Economou, Oreopoulou, \& Thomopoulos, 1991; Kaurinovic, Popovic, Vlaisavljevic, \& Trivic, 2011; Koşar, Dorman, \& Hiltunen, 2005; Spiridon, Bodirlau, \& Teaca, 2011; Özbek et al., 2008; Şahin et al., 2004; Škerget et al., 2005) and essential oils (Alinkina, Misharina, \& Fatkullina, 2012; Cekera et al., 2012; Quiroga et al., 2013; Şahin et al., 2004) have been reported. Nevertheless, studies using aqueous extracts are

* Corresponding authors. Tel.: +351 273 303219; fax: +351 273325405 (I. C.F.R Ferreira). Tel.: +351 273 303200; fax: +351 273325405 (L. Barros).

E-mail addresses: lillian@ipb.pt (L. Barros), iferreira@ipb.pt (I.C.F.R. Ferreira). scarce (Ličina et al., 2013), especially in decoction or infusion preparations traditionally used due to digestive, expectorant, antiseptic and antispasmodic properties (Vanaclocha \& Cañigueral, 2003). Some studies reported antibacterial activity of 0 . vulgare infusion and decoction (Chaudhry, Saeed, \& Tariq, 2007; Saeed \& Tariq, 2009), but using high concentrations (200 mg/mL and $100 \mathrm{mg} /$ $\mathrm{mL}$, respectively). In fact, the majority of reports regarding oregano antibacterial activity used essential oils (Bakkali et al., 2008; Orhan, Özçelík, Kartal, \& Kan, 2012; Rosato et al., 2009; Vale-Silva et al., 2012; Vanaclocha \& Cañigueral, 2003; Viuda-Martos, Ruiz-Navajas, Fernandez-Lopez, \& Perez-Alvarez, 2007), which in some cases are toxic and non-tolerated by patients. In general, essential oils tend to have side effects, in different degrees, and for this reason they should never be used undiluted. Oregano essential oil is an example, and despite its wide variety of applications, it could be used both internally and topically, but its application should be used with same precaution, due to photosensitive, neurotoxic and hepatotoxic effects. The main compounds present in oregano essential oil are phenolic monoterpenes, carvacrol and thymol (Bakkali et al., 2008; Sivropoulou, 1996). Those substances, at therapeutic doses, are beneficial during a small period of time, but they can be toxic to liver, kidneys and nervous system if taken in excess. According to Tisserand and Balacs (1995), oregano essential oil is never topically applied to mucous membranes in 
concentrations higher than $1 \%$, due to the possible irritating effect to the skin and even a possible burning effect. The same precaution should also be taken with individuals who have very sensitive or damaged skin, as well as with children less than two years of age, and during pregnancy, in which the oil application is not recommended (Longe, 2005; Tisserand \& Balacs, 1995; Vanaclocha \& Cañigueral, 2003). The most important cases in which the use of oregano essential oil is not recommend include patients with gastritis, gastroduodenal ulcers, ulcerative colitis and other inflammatory bowel diseases, liver disease, epilepsy, Parkinson's disease or other neurological dysfunctions. Furthermore, oregano essential oil should be used with caution in cases of patients with epilepsy, due to their potential neurotoxic and convulsing effects. Despite the absence of clinical studies, there are a few reports on the side effects of oregano essential oil. Cleff et al. (2008), evaluated the toxicity of $O$. vulgare essential oil administered orally and with intravaginal applications during 30 days, in adult females and Wistar rats, and concluded that $3 \%$ of the essential oil did not results in toxicological alterations. However, the authors recommend other studies namely, with different concentrations. Thus, oregano essential oil can be considered safe, when used correctly, never being taken internally, and topical applications should be performed after dilution, in a suitable carrier oil, and in low doses over a short period of time.

Therefore, the identification and characterization of other bioactive molecules (e.g., phenolic compounds) beside essential oils is demanded, particularly in forms (decoction and infusion) traditionally used for therapeutic applications. The aim of this work was to assess antioxidant and antibacterial efficacy of decoction, infusion and hydroalcoholic extract of $O$. vulgare and to carry out identification of main beneficial compounds, in terms of phenolic composition.

\section{Materials and methods}

\subsection{Sample}

Flowering aerial parts (leaves and flowers, separated from branches) of Origanum vulgare L., previously dried, supplied by Soria Natural (Garray - Soria, Spain), were obtained in September 2012. The sample was a clean product, with monitored parameters of pesticides, herbicides, heavy metals and radioactivity.

\subsection{Standards and reagents}

Methanol was of analytical grade purity and supplied by Pronalab (Lisbon, Portugal). 2,2-Diphenyl-1-picrylhydrazyl (DPPH) was obtained from Alfa Aesar (Ward Hill, MA, USA). HPLC-grade acetonitrile was obtained from Merck KgaA (Darmstadt, Germany). Formic and acetic acids were purchased from Prolabo (VWR International, France). The phenolic compound standards (apigenin 6-C-glucoside, chlorogenic acid, eriodictyol, kaempferol 3-O-glucoside, luteolin 7$\mathrm{O}$-glucoside, myricetin, protocatechuic acid, quercetin 3-O-glucoside, quercetin 3-O-rutinoside, rosmarinic acid, taxifolin) were from Extrasynthese (Genay, France). Trolox (6-hydroxy-2,5,7,8-tetramethylchroman-2-carboxylic acid) was purchased from Sigma Chemical Co. (St. Louis, MO, USA). Water was treated in a Milli-Q water purification system (TGI Pure Water Systems, Greenville, SC, USA).

\subsection{Preparation of the infusion, decoction and hydroalcoholic extract}

Hydroalcoholic extraction was performed using the plant material $(1 \mathrm{~g})$ stirring with $30 \mathrm{~mL}$ of methanol:water $(80: 20, v / v)$ at $25^{\circ} \mathrm{C}$ and $150 \mathrm{rpm}$ for $1 \mathrm{~h}$, and filtered through Whatman No. 4 paper. The residue was then extracted with one additional $30 \mathrm{~mL}$ portion of the hydroalcoholic mixture. The combined extracts were evaporated at $35^{\circ} \mathrm{C}$ under reduced pressure (rotary evaporator Büchi R-210, Flawil, Switzerland) and then further lyophilized (FreeZone 4.5, Labconco, Kansas City, MO, USA).

For infusion preparation, the sample $(1 \mathrm{~g})$ was added to $200 \mathrm{~mL}$ of boiling distilled water and left to stand at room temperature for $5 \mathrm{~min}$, and then filtered under reduced pressure. For decoction preparation, the sample $(1 \mathrm{~g})$ was added to $200 \mathrm{~mL}$ of distilled water, heated (heating plate, VELP scientific) and boiled for $5 \mathrm{~min}$. The mixture was left to stand for $5 \mathrm{~min}$ and then filtered under reduced pressure. The obtained infusions and decoctions were frozen and lyophilized. The lyophilized hydroalcoholic extract, was re-dissolved in methanol:water $(80: 20, v / v)$, while the infusion and decoction were re-dissolved in water, to obtain stock solutions of $20 \mathrm{mg} / \mathrm{mL}$.

\subsection{Evaluation of bioactivity}

\subsubsection{Antioxidant activity}

Four different in vitro assays were performed using serial dilutions of stock solution: scavenging effects on DPPH (2,2-diphenyl-1-picrylhydrazyl) radicals (RSA); reducing power (measured by ferricyanide Prussian blue assay) (RP); inhibition of $\beta$-carotene bleaching (CBI); and inhibition of lipid peroxidation in brain cell homogenates by TBARS (thiobarbituric acid reactive substances) assay (LPI).

RSA was evaluated using an ELX800 microplate Reader (Bio-Tek Instruments, Inc; Winooski, VT, USA), and calculated as a percentage of DPPH discolouration through the formula: $\left[\left(A_{\mathrm{DPPH}}-A_{\mathrm{S}}\right)\right.$ ] $\left.\mathrm{A}_{\mathrm{DPPH}}\right] \times 100$, where $A_{\mathrm{S}}$ is the absorbance of the solution containing the sample at $515 \mathrm{~nm}$, and $A_{\mathrm{DPPH}}$ is the absorbance of the DPPH solution. RP was evaluated by the capacity to convert $\mathrm{Fe}^{3+}$ into $\mathrm{Fe}^{2+}$, measuring the absorbance at $690 \mathrm{~nm}$ in the microplate Reader mentioned above. CBI was evaluated though the $\beta$-carotene/linoleate assay; the neutralization of linoleate free radicals avoids $\beta$-carotene bleaching, which is measured by the formula: $\beta$-carotene absorbance after $2 \mathrm{~h}$ of assay/initial absorbance) $\times 100$. LPI in pig (Sus scrofa) brain homogenates was evaluated by the decreasing in thiobarbituric acid reactive substances (TBARS); the color intensity of the malondialdehyde-thiobarbituric acid (MDA-TBA) abduct was measured by its absorbance at $532 \mathrm{~nm}$; the inhibition ratio (\%) was calculated using the following formula: $[(A-B) / A] \times 100 \%$, where $A$ and $B$ were the absorbance of the control and the sample solution, respectively. The results were expressed in $\mathrm{EC}_{50}$ values, i.e. sample concentration providing $50 \%$ of antioxidant activity or 0.5 of absorbance in the reducing power assay (Barros et al., 2010).

\subsubsection{Antibacterial activity}

To evaluate antibacterial activity different bacteria strains from American Type Culture Collection (ATCC) were used, namely Gram positive species, Staphylococcus aureus (ATCC 25923) and Staphylococcus epidermidis (ATCC 35983), and Gram negative species, Escherichia coli (ATCC 25922), Klebsiella spp., Pseudomonas aeruginosa (ATCC 10145), Enterococcus aerogenes (ATCC 2048), Proteus vulgaris (ATCC 6380) and Enterobacter sakazakii (ATCC 29544). The antibacterial effect was evaluated using the disc diffusion halo test (NCCLS/CLSI \& ANVISA, 2003). For that, each species was cultivated in a liquid medium, containing $30 \mathrm{~mL}$ of Tryptic Soy Broth (TSB), during $24 \mathrm{~h}$. After that, the concentration of each species was normalized for 0.5 of optical density (with approximately $1 \times 10^{7}$ cells $/ \mathrm{mL}$ ) by absorbance determination at $600 \mathrm{~nm}$. An aliquot of each species $(300 \mu \mathrm{L})$ was spread in Tryptic Soy Agar (TSA) petri dishes. Then, an aliquot of $25 \mu \mathrm{L}$ of each sample (decoction, infusion and hydroalcoholic extract- $20 \mathrm{mg} / \mathrm{mL}$ ), was placed on sterile blank disc. Sterile water was used as negative control. The plates were incubated at $37^{\circ} \mathrm{C}$, during $24-48 \mathrm{~h}$. Antibacterial activity 
was measured using a qualitative method, based on disc diffusion assay. In this study, the qualitative results were converted in a semi-quantitative scale being classified the distinctness of the halo as: (-) absence of halo; (+) weak halo; (++) moderate halo; (+++) strong halo. Absence of halo concerning to $0.0 \mathrm{~mm}$; weak halo between 0.3 and $0.7 \mathrm{~mm}$; moderate halo $8-1.0 \mathrm{~mm}$, and strong halo greater than $1.1 \mathrm{~mm}$.

\subsection{Analysis of phenolic compounds}

Phenolic compounds were determined by HPLC (Hewlett-Packard 1100, Agilent Technologies, Santa Clara, CA, USA) as previously described by Barros et al. (2013a). Double online detection was carried out in the diode array detector(DAD) using $280 \mathrm{~nm}$ and $370 \mathrm{~nm}$ as preferred wavelengths and in a mass spectrometer (MS) connected to the HPLC system via the DAD cell outlet. The phenolic compounds present in the samples were characterised according to their UV and mass spectra and retention times compared with commercial standards when available. The phenolic compounds were identified by comparing their retention time, UV-vis and mass spectra with those obtained from standard solutions, when available. Otherwise, peaks were tentatively identified comparing the obtained information with available data reported in the literature. For quantitative analysis, a calibration curve $(1-100 \mathrm{~g} / \mathrm{mL})$ for each available phenolic standard was constructed based on the UV signal: apigenin-6-C-glucoside $\left(y=517.4 \mathrm{x}+268.26 ; R^{2}=0.9921\right)$; chlorogenic acid $\left(y=313.03 \mathrm{x}-58.2 ; R^{2}=0.999\right)$; kaempferol 3-Oglucoside $\left(y=288.55 \mathrm{x}-4.0503 ; R^{2}=1\right)$; kaempferol 3-O-rutinoside $\left(y=239.16 \mathrm{x}-10.587 ; \quad R^{2}=1\right) ; \quad$ luteolin 7 -O-glucoside $\left(y=80.829 \mathrm{x}-21.291 ; R^{2}=0.999\right) ;$ myricetin $(y=741.41 \mathrm{x}-221.6$; $\left.R^{2}=0.999\right) ;$ protocatechuic acid $\left(y=291.1 \mathrm{x}-6.4558 ; R^{2}=0.999\right)$; quercetin 3-O-glucoside $\left(y=363.45 \mathrm{x}+117.86 ; R^{2}=0.9994\right)$, quercetin 3-O-rutinoside $\left(y=281.98 \mathrm{x}-0.3459 ; R^{2}=1\right)$; rosmarinic acid $\left(y=336.03 \mathrm{x}+170.39 ; \quad R^{2}=0.999\right)$ and taxifolin $(y=478.06 \mathrm{x}+$ 657.33; $\left.R^{2}=0.999\right)$. For the identified phenolic compounds for which a commercial standard was not available, the quantification was performed through the calibration curve of other compound from the same phenolic group. The results were expressed in $\mathrm{mg}$ per $g$ of extract.

\subsection{Statistical analysis}

All the samples of oregano (infusion, decoction and hydroalcoholic extract) were prepared and analyzed in triplicate. The results, expressed as mean values and standard deviation (SD), were analyzed using one-way analysis of variance (ANOVA) followed by Turkey's HSD Test with $\alpha=0.05$, performed with SPSS (Statistical Package for the Social Sciences) v. 22.0 program (IBM).

\section{Results and discussion}

\subsection{Evaluation of antioxidant activity}

The antioxidant properties were evaluated by determining reducing power (RP), free radicals scavenging activity (RSA), $\beta$-carotene bleaching inhibition (CBI) and lipid peroxidation inhibition (LPI) in brain cell homogenates. The results are shown in Table 1 . The infusion and decoction samples presented similar RP and RSA, but the decoction gave higher CBI and LPI than the infusion. Both preparations (infusion and decoction) gave, in all the performed assays, higher antioxidant activity than the hydroalcoholic extract. Therefore, the compounds with stronger antioxidant activity in oregano seem to be water-soluble.

It should be highlighted that infusions can be used in a wide range of medical conditions by the majority of people without causing any adverse/toxic effect, not only by internal but also by external use (EFSA, 2010). Nevertheless, European Commission and other health organizations consider that due to the lack of an adequate dossier, the safety of oregano and other medicinal plants cannot be assessed (EFSA, 2010). Thus, their use for medicinal purposes should be avoided in the absence of therapeutic indications. However, it should be noted that the use of oregano as spice, herbal food ingredient and in folk medicine has a safe history, being cited since ancient times (Longe, 2005; Vanaclocha \& Cañigueral, 2003). In fact, due to the extensive culinary use, oregano is listed as Generally Recognised As Safe (GRAS), in the Code of Federal Regulations (http://www.ecfr.gov/cgi-bin/ECFR) and had never been restricted by any worldwide authority. European Food and Safety Authority (EFSA) reports a high antioxidant efficacy of oregano as food additive, but without a dossier supporting its use and reporting safety levels (EFSA, 2010).

Alinkina et al. (2012) described a higher antioxidant activity of oregano essential oils compared to individual phenols (thymol and carvacrol), which means that other important compounds have interactions and establish a synergic effect. Similar results were shown by Quiroga et al. (2013), comparing the chemical composition, antioxidant and anti-lipase activities of $O$. vulgare and Lippia turbinate essential oils. The authors concluded that, despite the similarity in the antioxidant activity of both essential oils, oregano showed higher anti-lipase and scavenging activities than Lippia, attributing those properties to its higher phenolic content. Şahin et al. (2004) also described strong free radicals scavenging properties of oregano methanolic extract (due to phenolic content), but a weaker activity of its essential oils. They also observed that a methanolic extract did not effectively inhibited linoleic acid oxidation (Şahin et al., 2004). This should be in agreement with our study, in which the hydroalcoholic extract showed lower inhibitory activity of $\beta$-carotene bleaching (CBI EC $50371.45 \pm 12.40 \mu \mathrm{g} / \mathrm{mL}$ ) than radical scavenging activity (RSA value $246.45 \pm 24.00 \mu \mathrm{g} / \mathrm{mL}$ ).

Other authors, reporting the antioxidant activity of some plant extracts of the family Lamiaceae, including oregano, attributed their scavenging activity to phenolic and flavonoid contents (Economou et al., 1991; Kaurinovic et al., 2011; Spiridon et al., 2011; Škerget et al., 2005). Furthermore, Kaurinovic et al. (2011) also described strong antioxidant effects for oregano aqueous extracts in comparison with organic extracts, which is in accordance with our experiment where decoction and infusion gave higher antioxidant activity than the hydroalcoholic extract. The antioxidant activity reported by Barros et al. (2010) for a methanolic extract obtained from wild oregano was, in general, higher

Table 1

Antioxidant activity $\left(\mathrm{EC}_{50}\right.$ values, $\mu \mathrm{g} / \mathrm{mL}$ ) of infusion, decoction and hydroalcoholic extract of Origanum vulgare $\mathrm{L}$. (mean $\pm \mathrm{SD}$ ).

\begin{tabular}{|c|c|c|c|}
\hline & Infusion & Decoction & Hydroalcoholic extract \\
\hline DPPH scavenging activity (RSA) & $142.43 \pm 10.30^{\mathrm{a}}$ & $132.93 \pm 6.61^{\mathrm{a}}$ & $246.45 \pm 24.00^{\mathrm{b}}$ \\
\hline Reducing power (RP) & $116.26 \pm 0.45^{a}$ & $111.06 \pm 8.16^{\mathrm{a}}$ & $237.45 \pm 8.51^{\mathrm{b}}$ \\
\hline$\beta$-carotene bleaching inhibition (CBI) & $262.30 \pm 2.58^{\mathrm{b}}$ & $115.69 \pm 16.34^{\mathrm{c}}$ & $371.45 \pm 12.40^{\mathrm{a}}$ \\
\hline TBARS inhibition (LPI) & $22.75 \pm 0.54^{\mathrm{b}}$ & $8.73 \pm 0.55^{c}$ & $33.66 \pm 2.93^{\mathrm{a}}$ \\
\hline
\end{tabular}

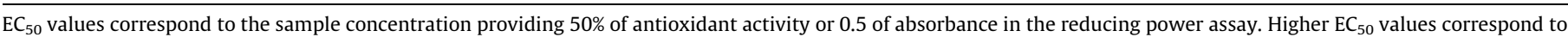
lower antioxidant activity.

In each row different letters mean significant differences $(\mathrm{p}<0.05)$. 
than the one shown by hydroalcoholic extract, but lower than antioxidant properties of infusion/decoction.

\subsection{Evaluation of antibacterial activity}

The results obtained in the screening of antibacterial activity by disc diffusion halo assay are present in Table 2 . The results revealed that the samples were, in general, effective against the gram-negative and gram-positive bacteria tested, despite the most pronounced effect was observed against the gram-negative bacteria, specifically $E$. coli and $P$. aeruginosa. It was very interesting to observe the variability among the different species of the same genus tested, namely Enterobacter spp. and Staphilococcus spp, gram-negative and gram-positive bacteria, respectively. In fact, the effect was opposite in the two species of each genus.

Decoction and infusion had similar potential against almost all the tested bacteria, whereas the hydroalcoholic extract showed relatively higher efficacy against some strains (namely, E. coli and P. vulgaris) than the former. Chaudhry et al. (2007), using an essential oil, infusion and decoction of oregano, reported inhibitory effects against gram-negative bacteria (Aeromonas hydrophila, Citrobacter spp., E. aerogenes, E. coli, Flavobacterium spp., Klebsiella ozaenae, Klebsiella pneumoniae, P. mirabilis, P. aeruginosa, Salmonella typhi, S. paratyphi B, Serratia marcescens and Shigella dysenteriae). The highest inhibitory activity was obtained using essential oil against Citrobacter spp., whereas infusion showed inhibitory activity against all type of bacteria strains, namely Klebsiella pneumonia, Klebsiella ozaenae and Enterobacter aerogenes. All the bacteria showed resistance to oregano decoction. Despite in our experiment no antibacterial activity has been detected against Klebsiella spp., it should be highlighted that the concentration used $(20 \mathrm{mg} / \mathrm{mL})$ was considerably lower than the tested by those authors $(200 \mathrm{mg} / \mathrm{mL})$ (Chaudhry et al., 2007). Moreover, the results obtained under this study showed antibacterial activity by the decoction $(20 \mathrm{mg} / \mathrm{mL})$ against E. aerogenes, E. coli and P. aeruginosa. Saeed and Tariq (2009) found that the infusion was more effective than the essential oil of oregano against gram-positive bacteria (Staphylococcus saprophyticus, S. aureus, Micrococcus roseus, M. kristinae, M. nishinomiyaensis, M. lyla, M. luteus, M. sedentarius, M. varians, Bacillus megaterium, B. thuringiensis, B. alvei, B. circulans, B. brevis, B. coagulans, B. pumilus, B. laterosporus, B. polymyxa, B. macerans, $B$. subtilis, $B$. firmus, $B$. cereus and $B$. lichiniformis) whereas no antibacterial activity was found using oregano decoction $(100 \mathrm{mg} / \mathrm{mL})$.

\subsection{Analysis of phenolic compounds}

The phenolic profile of 0 . vulgare, obtained after hydroalcoholic extraction, and recorded at $370 \mathrm{~nm}$ is shown in Fig. 1; peak characteristics and tentative identities are presented in Table 3. Twenty two compounds were detected, six of which were phenolic acid derivatives and sixteen flavonoids. Protocatechuic (peak 2), 5-O-caffeoylquinic (peak 3) and rosmarinic acid (peak 15) were positively identified according to their retention, mass and
UV-vis characteristics by comparison with commercial standards. Peak $1\left([\mathrm{M}-\mathrm{H}]^{-}\right.$at $m / z$ 353) was identified as 3-O-caffeoylquinic acid, yielding the base peak at $m / z 191$ and the ion at $m / z 179$ with an intensity $>66 \%$ base peak, characteristic of 3-acylchlorogenic acids as reported by Clifford, Johnston, Knight, and Kuhnert (2003) and Clifford, Knight, \& Kuhnert, 2005). Peak 8 presented a pseudo molecular ion $[\mathrm{M}-\mathrm{H}]^{-}$at $m / z 421$, yielding a unique fragment ion at $m / z$ 153. Nakatani and Kikuzaki (1987) identified a compound with the same molecular weight in 0 . vulgare as 4-(3,4-dihydroxybenzoyloxymethyl)phenyl- $\beta$-D-glucopyranoside and recently, Zhang et al. (2014) also identified and isolated a similar compound in 0 . vulgare, with the same molecular weight and UV spectra, as 4-[[(2',5'-dihydroxybenzoyl)oxy]methyl]phenyl $O$ - $\beta$-D-glucopyranoside. A compound with the same mass and UV characteristics was also identified by Miron, Plaza, Bahrim, Ibáñez, and Herrero (2011) as protocatechuic acid hexoside, although such a structure should be wrong as it does not match with its molecular ion and no discussion is made in the paper about the reasons for giving that identity. Furthermore, it would not be logical a hexoside elute later than the parent phenolic acid. Thus, the peak could be assigned as 4-[[( $2^{\prime}, 5^{\prime}$-dihydroxybenzoyl $)$ oxy $]$ methyl]phenyl $O-\beta$-D-glucopyranoside, due to its similar UV and MS spectra.

Peak 19 presented a pseudo molecular ion $[\mathrm{M}-\mathrm{H}]^{-}$at $m / z 537$ and a UV spectrum and fragmentation pattern consistent with the caffeic acid trimer lithospermic acid A. This compound can easily lose 8"-carboxyl group (-44 mu) releasing a fragment at $m / z 493$ that further breaks down to form the fragment ions at $m / z 313$ and 295 (Barros et al., 2013b). Salvianolic acids H/I, with the same molecular weight as lithospermic acid A, were discarded as possible identities because they present quite a different fragmentation pattern (Ruan, Li, Li, Luo, \& Kong, 2012).

Myricetin 3-O-glucoside (peak 6), taxifolin (peak 9), quercetin 3-O-rutinoside (peak 10), luteolin 7-O-glucoside (peak 13), eridictyol (peak 20) and naringenin (peak 22) were positively identified according to their retention, mass and UV-vis characteristics by comparison with commercial standards.

Peak 12 presented a UV spectrum characteristic of luteolin $\left(\lambda_{\max }\right.$ at $350 \mathrm{~nm}$ ) and a pseudo molecular ion $[\mathrm{M}-\mathrm{H}]^{-}$at $m / z 461$, releasing fragments at $\mathrm{m} / \mathrm{z} 285$ ([M-176 $]^{-}$, loss of a glucuronyl moiety), being identified as luteolin $O$-glucuronide. Peaks 4,14 and 16 were identified as apigenin derivatives according to their UV and mass spectra characteristics. Peak 4 presented a pseudo molecular ion $[\mathrm{M}-\mathrm{H}]^{-}$at $m / z 593$, releasing three $\mathrm{MS}^{2}$ fragment ions at $m / z 473$ and 383, corresponding to the loss of 120 and 90 mu characteristic of $C$-hexosyl flavones, and at $m / z 353$ that would correspond to the apigenin aglycone bearing some sugar residues [apigenin $+83 \mathrm{mu}$ ] (Ferreres, Silva, Andrade, Seabra, \& Ferreira, 2003). The fact that no relevant fragment derived from the loss of a complete hexosyl residue $(-162 \mathrm{mu})$ was detected suggested that both sugars were $C$-attached, which allowed a tentative identification of the compound as apigenin $C$-hexoside $C$-hexoside. This compound can be identified as apigenin 6,8-di-C-glucoside (vicenin-2) previously identified in Origanum vulgare by Grevsen, Fretté, and Christensen

Table 2

Antibacterial activity of infusion, decoction and hydroalcoholic extract of Origanum vulgare L. against several bacterial species.

\begin{tabular}{|c|c|c|c|c|}
\hline Antibacterial activity & & Infusion $(20 \mathrm{mg} / \mathrm{mL})$ & Decoction $(20 \mathrm{mg} / \mathrm{mL})$ & Hydroalcoholic extract $(20 \mathrm{mg} / \mathrm{mL})$ \\
\hline \multirow[t]{2}{*}{ Gram positive } & Staphylococcus aureus & - & - & - \\
\hline & Staphylococcus epidermidis & + & + & + \\
\hline \multirow[t]{6}{*}{ Gram negative } & Escherichia coli & ++ & + & +++ \\
\hline & Klebsiella spp. & - & - & - \\
\hline & Pseudomonas aeruginosa & + & ++ & ++ \\
\hline & Enterobacter aerogenes & - & + & - \\
\hline & Enterobacter sakazakii & + & + & + \\
\hline & Proteus vulgaris & + & + & ++ \\
\hline
\end{tabular}

(-) absence of halo; (+) weak halo; (++) moderate halo; (+++) strong halo. 


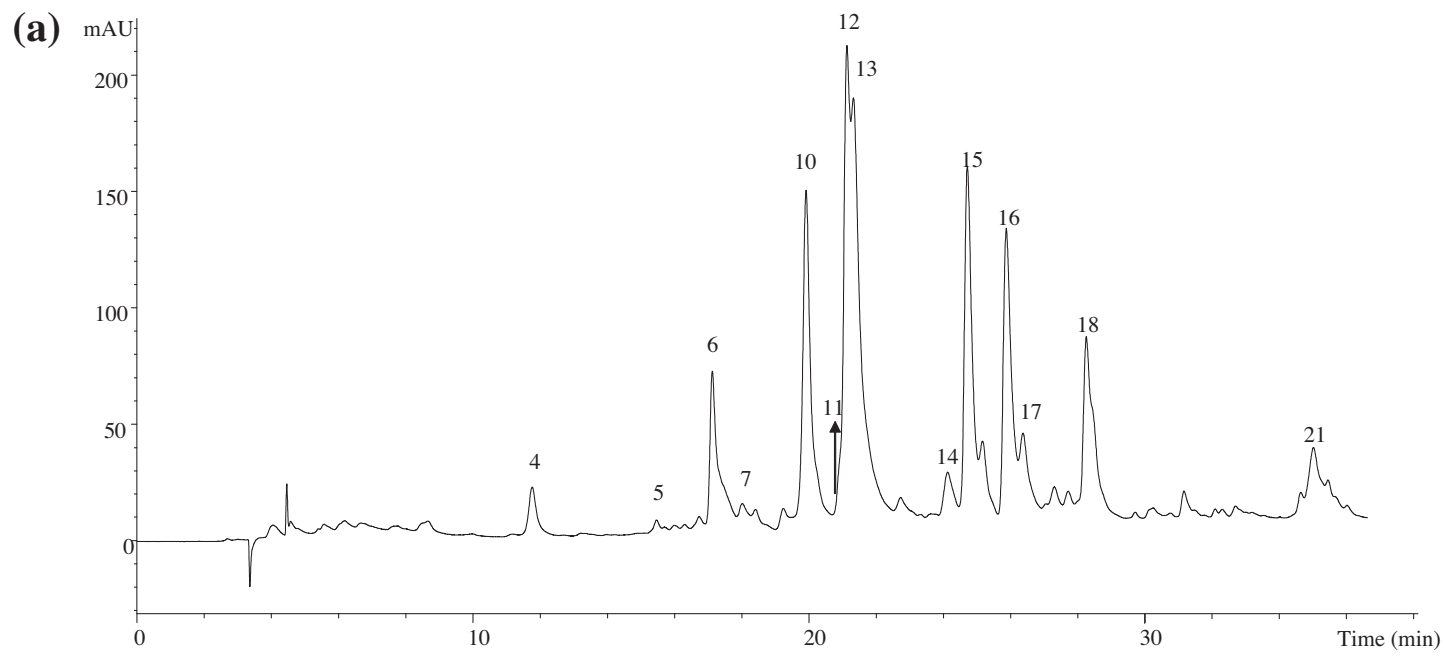

(b)

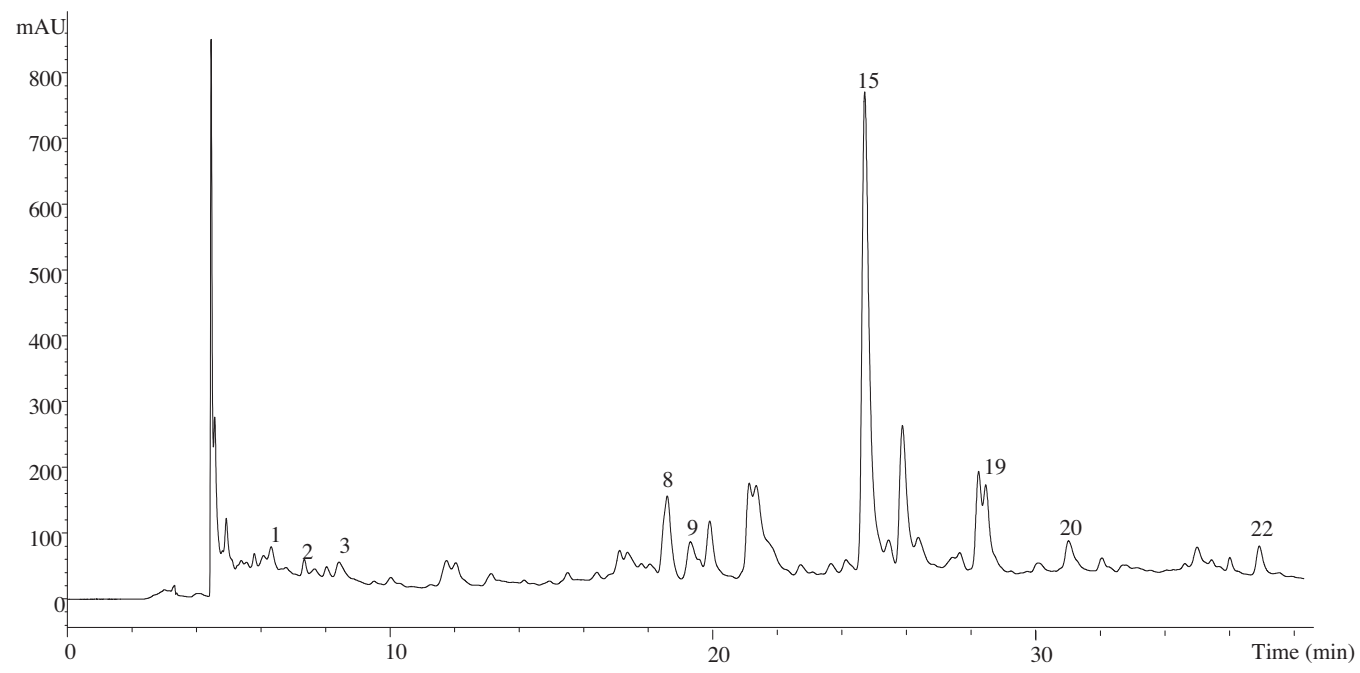

Fig. 1. Phenolic profile of Origanum vulgare L. hydroalcoholic extract recorded at $370 \mathrm{~nm}$ (a) and $280 \mathrm{~nm}$ (b).

(2009) and Koukoulitsa et al. (2006); and has also been described to be a normal constituent of 0 . vulgare. Peaks 14 and 16 showed pseudo molecular ions $[\mathrm{M}-\mathrm{H}]^{-}$at $\mathrm{m} / z 577$ and 445, respectively, both releasing an $\mathrm{MS}^{2}$ fragment at $\mathrm{m} / \mathrm{z} 269$ ([M-308 $^{-}$and $[\mathrm{M}-176]^{-}$, respective losses of rutinosyl and glucuronyl moieties). These compounds were tentatively assigned as apigenin 7-O-rutinoside and apigenin 7-O-glucuronide as they were previously identified in oregano by Hossain, Rai, Brunton, Martin-Diana, and Barry-Ryan (2010) and Grevsen et al. (2009).

Peak 21 showed a pseudo molecular ion $[\mathrm{M}-\mathrm{H}]^{-}$at $\mathrm{m} / \mathrm{z} 459$, releasing two $\mathrm{MS}^{2}$ fragments at $283\left([\mathrm{M}-176]^{-}\right.$, loss of a glucuronyl moiety) and 268 (apigenin, further loss of a methyl residue), being tentatively assigned as methylapigenin $O$-glucuronide. The presence of acacetin (4'-O-methylapigenin) and another methylapigenin in oregano was reported by Hossain et al. (2010).

Pseudo molecular ([M-H $]^{-}$at $\left.m / z 463\right)$ and product $(m / z$ at 301 , quercetin) ions of peaks 7 and 11 allowed their identification as quercetin $O$-hexosides. Peak 11 showed $\lambda_{\max }$ at higher wavelength $(368 \mathrm{~nm})$ than quercetin $3-0$-glucoside $(344 \mathrm{~nm})$ and similar to quercetin aglycone. According to Mabry, Markham, and Thomas (1970), the introduction of a glycoside on the hydroxyls at positions $7,3^{\prime}$ or $4^{\prime}$ should not have effect on maximal wavelength or the spectrum shape in relation to the aglycone. Thus, peak 11 was tentatively assigned as quercetin 7-O-hexoside. An undefined quercetin 3-O-hexoside was also reported to occur in oregano by Hossain et al. (2010).

Peaks 5 and 17 were identified as kaempferol derivatives, according to their UV and mass spectra characteristics. Peak 5 showed a pseudo molecular ion $[\mathrm{M}-\mathrm{H}]^{-}$at $m / z 609$, releasing two $\mathrm{MS}^{2}$ fragments at $m / z 447$ ([M-H-162 $]^{-}$, loss of a hexosyl moiety) and 285 (kaempferol; [M-H-162-162 $]^{-}$, loss of a further hexosyl moiety), being identified as kaempferol $O$-hexosyl- $O$-hexoside. Peak 17 presented a pseudo molecular ion at $m / z 447$ and a $\mathrm{MS}^{2}$ fragment at $m / z 285$ (kaempferol; [M-H-162-162 $]^{-}$, loss of a further hexosyl moiety), being identified as kaempferol $O$-hexoside. Peak 18 presented a pseudo molecular ion $[\mathrm{M}-\mathrm{H}]^{-}$at $m / z 475$, yielding fragment ions at $m / z 299$ and 284, associated to the loss of a glucuronyl moiety (176 mu) and a further $-\mathrm{CH}_{3}$ group (15 mu), which allowed its tentative identification as kaempferide $\mathrm{O}$-glucuronide.

From the 22 compounds identified, six were phenolic acids being rosmarinic acid the most abundant in all the preparations. The remaining compounds were flavonoid derivatives, being luteolin 7-O-glucoside (hydroalcoholic acid) and luteolin $\mathrm{O}$-glucuronide (infusion and decoction) the most abundant compounds found. Decoction presented the highest concentration of flavonoids (75.25 mg/g decoction) and total phenolic compounds $(98.05 \mathrm{mg} / \mathrm{g}$ decoction), followed by infusion and hydroalcoholic extract, respectively. This is also in agreement with the results obtained 
Table 3

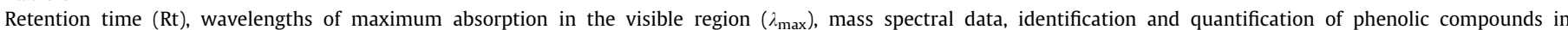
hydroalcoholic extract, infusion and decoction of Origanum vulgare $\mathrm{L}$.

\begin{tabular}{|c|c|c|c|c|c|c|c|c|}
\hline \multirow[t]{2}{*}{ Peak } & \multirow{2}{*}{$\begin{array}{l}\text { Rt } \\
(\min )\end{array}$} & \multirow{2}{*}{$\begin{array}{l}\lambda_{\max } \\
(\mathrm{nm})\end{array}$} & \multirow{2}{*}{$\begin{array}{l}\text { Molecularion } \\
{[\mathrm{M}-\mathrm{H}]^{-}(m / z)}\end{array}$} & \multirow[t]{2}{*}{$\mathrm{MS}^{2}(m / z)$} & \multirow[t]{2}{*}{ Identification } & \multicolumn{3}{|c|}{ Quantification (mg/g extract) } \\
\hline & & & & & & Hydroalcoholic & Infusion & Decoction \\
\hline 1 & 5.79 & 328 & 353 & $\begin{array}{l}\text { 191(100), 179(66), 173(4), } \\
135(45)\end{array}$ & 3-O-Caffeolyquinic acid & $0.37 \pm 0.07$ & $0.64 \pm 0.01$ & $0.55 \pm 0.07$ \\
\hline 2 & 6.31 & $\begin{array}{l}260 \\
\operatorname{sh} 294\end{array}$ & 153 & 123(8), 109(100) & Protocatechuic acid & $0.63 \pm 0.06$ & $1.07 \pm 0.05$ & $1.02 \pm 0.06$ \\
\hline 3 & 8.67 & 328 & 353 & $\begin{array}{l}\text { 191(100), 179(4), 173(2), 161(4), } \\
135(2)\end{array}$ & 5-O-Caffeolyquinic acid & $0.92 \pm 0.04$ & $0.96 \pm 0.01$ & $0.81 \pm 0.03$ \\
\hline 4 & 11.75 & 330 & 593 & 473(16), 383(10), 353(16), 297(2) & Apigenin 6,8-di-C-glucoside & $0.52 \pm 0.06$ & $0.92 \pm 0.00$ & $0.98 \pm 0.00$ \\
\hline 5 & 15.46 & 340 & 609 & 447(100), 285(12) & Kaempferol $O$-hexosyl- $O$-hexoside & $0.15 \pm 0.01$ & $0.22 \pm 0.01$ & $0.21 \pm 0.01$ \\
\hline 6 & 17.12 & 360 & 479 & $317(100)$ & Myricetin 3-O-glucoside & $0.58 \pm 0.01$ & $0.52 \pm 0.00$ & $0.58 \pm 0.00$ \\
\hline 7 & 18.01 & 344 & 463 & $301(100)$ & Quercetin 0 -hexoside & $0.41 \pm 0.03$ & $0.61 \pm 0.02$ & $0.57 \pm 0.03$ \\
\hline 8 & 18.58 & $\begin{array}{l}264 \\
\operatorname{sh} 290\end{array}$ & 421 & $153(100)$ & $\begin{array}{l}\text { 4-[[(2',5' } \\
\text { Dihydroxybenzoyl)oxy]methyl]phenyl } \\
\text { O- } \beta \text {-D-glucopyranoside }\end{array}$ & $3.46 \pm 0.05$ & $2.11 \pm 0.16$ & $2.54 \pm 0.22$ \\
\hline 9 & 19.31 & 290 & 303 & 285(80), 125(100) & Taxifolin & $0.47 \pm 0.02$ & $0.31 \pm 0.05$ & $0.38 \pm 0.38$ \\
\hline 10 & 19.91 & 354 & 609 & $301(100)$ & Quercetin 3-O-rutinoside & $3.71 \pm 0.01$ & $2.88 \pm 0.02$ & $3.16 \pm 0.07$ \\
\hline 11 & 20.80 & 368 & 463 & $301(100)$ & Quercetin 7-O-hexoside & $0.54 \pm 0.07$ & nd & nd \\
\hline 12 & 21.12 & 350 & 461 & $285(100)$ & Luteolin $O$-glucuronide & $12.48 \pm 0.09$ & $26.50 \pm 0.15$ & $28.27 \pm 0.24$ \\
\hline 13 & 21.32 & 348 & 447 & $285(100)$ & Luteolin 7-O-glucoside & $20.88 \pm 0.00$ & $22.93 \pm 0.83$ & $25.26 \pm 0.44$ \\
\hline 14 & 24.12 & 332 & 577 & $269(100)$ & Apigenin 7-O-rutinoside & $1.53 \pm 0.06$ & $0.74 \pm 0.00$ & $1.09 \pm 0.07$ \\
\hline 15 & 24.71 & 330 & 359 & $\begin{array}{l}\text { 197(49), 179(45), 161(100), } \\
135(21)\end{array}$ & Rosmarinic acid & $14.62 \pm 0.03$ & $15.91 \pm 0.34$ & $15.42 \pm 0.15$ \\
\hline 16 & 25.87 & 338 & 445 & $269(100)$ & Apigenin 7-O-glucuronide & $5.78 \pm 0.03$ & $8.24 \pm 0.48$ & $8.63 \pm 0.02$ \\
\hline 17 & 26.37 & 340 & 447 & $285(100)$ & Kaempferol $O$-hexoside & $1.30 \pm 0.03$ & $0.67 \pm 0.21$ & $0.76 \pm 0.06$ \\
\hline 18 & 28.25 & 354 & 475 & 299(100), 284(47) & Kaempferide $O$-glucuronide & $1.58 \pm 0.11$ & $3.99 \pm 0.03$ & $3.97 \pm 0.02$ \\
\hline 19 & 28.46 & 328 & 537 & $\begin{array}{l}\text { 493(100), 359(88),313(10), } \\
\text { 295(53), 197(16), 179(35), } \\
\text { 161(73), 135(50) }\end{array}$ & Lithospermic acid A & $2.33 \pm 0.10$ & $2.20 \pm 0.05$ & $2.45 \pm 0.16$ \\
\hline 20 & 31.02 & 288 & 287 & 151(90), 135(100) & Eridictyol & $0.85 \pm 0.01$ & $0.22 \pm 0.05$ & $0.30 \pm 0.08$ \\
\hline 21 & 35.01 & 342 & 459 & 283(100), 269(12) & Methylapigenin $\mathrm{O}$-glucuronide & $1.26 \pm 0.13$ & $0.61 \pm 0.02$ & $0.79 \pm 0.01$ \\
\hline \multirow[t]{4}{*}{22} & 36.94 & $\begin{array}{l}288 \\
\operatorname{sh} 334\end{array}$ & 271 & 151(90), 119(73) & Naringenin & $0.43 \pm 0.04$ & $0.17 \pm 0.03$ & $0.29 \pm 0.01$ \\
\hline & & & & & Phenolic acids & $22.33 \pm 0.07^{\mathrm{a}}$ & $22.89 \pm 0.39^{a}$ & $22.80 \pm 0.62^{\mathrm{a}}$ \\
\hline & & & & & Flavonoids & $52.47 \pm 0.18^{\mathrm{c}}$ & $69.52 \pm 0.74^{\mathrm{b}}$ & $75.25 \pm 0.54^{\mathrm{a}}$ \\
\hline & & & & & Total phenolic compounds & $74.79 \pm 0.11^{\mathrm{c}}$ & $92.40 \pm 0.35^{\mathrm{b}}$ & $98.05 \pm 1.16^{\mathrm{a}}$ \\
\hline
\end{tabular}

In each row different letters mean significant differences $(\mathrm{p}<0.05)$.

for antioxidant activity, where decoction presented the highest activity. The concentration of phenolic acids did not present significant variation between the three different preparations.

There are several publications reporting the phenolic composition of $O$. vulgare from different origins and using different extraction methodologies. Nevertheless, none of those samples exhibited the same phenolic profile, presenting only few similarities in some of the compounds identified (Agiomyrgianaki \& Dais, 2012; Grevsen et al., 2009; Hossain et al., 2010; Miron et al., 2011; Rodríguez-Meizoso et al., 2006; Shen et al., 2010; Skoula, Grayer, Kite, \& Veitch, 2008). Miron et al. (2011) presented the phenolic composition of 0 . vulgare from Romania after pressurized liquid extraction with water and ethanol. Those authors identified twelve compounds: eight phenolic acids namely, syringic acid, protocatechuic acid, protocatechuic glucoside, homovanillic acid, hydroxybenzoic acid, caffeic acid, rosmarinic acid and caffeic acid ethyl ester; and four flavonoids namely, luteolin 7-O-glucuronide, apigenin, luteolin, and naringenin. That study did not present any quantification, however, by the chromatographic profile showed in the paper, rosmarinic acid seemed to be the most abundant compound. Rodríguez-Meizoso et al. (2006) studied dried oregano leaves from Spain, using subcritical water extraction, but these authors did not present any quantification nor identification of the phenolic compounds, only proposing the chemical family for some compounds (flavanones, dihydroflavonols, flavonols and flavones). Agiomyrgianaki and Dais (2012) analysed a sample of $O$. vulgare from Greece, using ethanol and ethyl acetate as extraction solvents. These authors identified and quantified nine phenolic compounds namely, ferulic acid, apigenin, oleanolic acid, ursolic acid, rosmarinic acid, chlorogenic acid, naringenin, eriodictyol and taxifolin. Shen et al. (2010) only described the presence of rosmarinic, oleanolic and ursolic acids in samples of $O$. vulgare from Greece and in another unspecific sample from Europe. Rosmarinic acid was the most abundant compound found in all the studied samples.

Skoula et al. (2008) reported the presence of fourteen phenolic compounds in a sample from Greece, extracted with ethanol. That study presented a variety of different phenolic compounds that were not identified in the other studies mentioned above, and also from the ones identified herein. The authors presented four similar phenolic compounds namely apigenin, naringenin, eriodictyol and taxifolin.

Moreover, Hossain et al. (2010) reported the presence of thirty four phenolic compounds (fourteen phenolic acids, fifteen flavonoids and five other phenolic compounds) in a sample from Ireland, extracted with aqueous methanol (80\%), using a homogenizer and shaken overnight. The phenolic compounds identified in this study presented similarities to the identifications performed by Hossain et al. (2010), but some differences were observed, especially regarding phenolic acids. Grevsen et al. (2009) identified nineteen phenolic compounds (five phenolic acids and fourteen flavonoids) in a sample of 0 . vulgare ssp. Hirtum (Greek oregano) cultivated in cool temperature climate in Denmark. They performed a similar extraction procedure as Hossain et al. (2010) and the compounds identified were slightly similar to the ones found in this study.

Overall, there is diversity in the characterization of the phenolic compounds of samples from different countries and using different extraction procedures. Nevertheless, the infusion and 
decoction of 0 . vulgare were never characterized nor quantified, until now.

Both preparations, mostly decoction, gave higher antioxidant activity than the hydroalcoholic extract. The antioxidant properties seem to be related to phenolic compounds, mainly flavonoids, since decoction presented the highest concentration of flavonoids and total phenolic compounds, followed by infusion and hydroalcoholic extract, respectively. Phenolic acids content (found in lower amounts in comparison with flavonoids) did not varied among different samples. Rosmarinic acid was the most abundant phenolic acid in all the preparations, while luteolin 7-O-glucoside (hydroalcoholic acid) and luteolin $O$-glucuronide (infusion and decoction) were the most abundant flavonoids. Furthermore, all the samples were effective against gram-negative and gram-positive bacteria, but the most pronounced effect was observed against the gramnegative bacteria, E. coli and $P$. aeruginosa. The hydroalcoholic extract showed a higher efficacy against some species namely, E. coli and P. vulgaris, while decoction and infusion had similar antimicrobial potential.

This study confirms the bioactive potential of oregano besides its use as food condiment; the decoction could be used for antioxidant purposes, while the hydroalcoholic extract could be incorporated in formulations for antimicrobial features. Moreover, the use of infusion/decoction, by internal or external use, can avoid the toxic effects showed by other oregano fractions such as essential oil. Further studies should be performed in order to establish in vivo bioactive properties.

\section{Acknowledgements}

The authors are grateful to Foundation for Science and Technology (FCT, Portugal) for N. Martins Grant (SFRH/BD/87658/2012), L. Barros researcher contract under "Programa Compromisso com Ciência - 2008" and financial support to the research centre CIMO (Strategic Project PEst-OE/AGR/UI0690/2011).

\section{References}

Agiomyrgianaki, A., \& Dais, P. (2012). Simultaneous determination of phenolic compounds and triterpenic acids in oregano growing wild in Greece by 31P NMR spectroscopy. Magnetic Resonance in Chemistry, 50, 739-748.

Albano, S. M., \& Miguel, M. G. (2011). Biological activities of extracts of plants grown in Portugal. Industrial Crops and Products, 33, 338-343.

Alinkina, E. S., Misharina, T. A., \& Fatkullina, L. D. (2012). Antiradical properties of oregano, thyme, and savory essential oils. Applied Biochemistry and Microbiology, 49, $73-78$.

Bakkali, F., Averbeck, S., Averbeck, D., \& Idaomar, M. (2008). Biological effects of essential oils - A review. Food and Chemical Toxicology, 46, 446-475.

Barros, L., Alves, C. T., Dueñas, M., Silva, S., Oliveira, R., Carvalho, A. M., et al. (2013a). Characterization of phenolic compounds in wild medicinal flowers from Portugal by HPLC-DAD-ESI/MS and evaluation of antifungal properties. Industrial Crops and Products, 44, 104-110.

Barros, L., Dueñas, M., Dias, M. I., Sousa, M. J., Santos-Buelga, C., \& Ferreira, I. C. F. R (2013b). Phenolic profiles of cultivated, in vitro cultured and commercia samples of Melissa officinalis L. infusions. Food Chemistry, 136, 1-8.

Barros, L., Heleno, S. A., Carvalho, A. M., \& Ferreira, I. C. F. R. (2010). Lamiaceae often used in Portuguese folk medicine as a source of powerful antioxidants: Vitamins and phenolics. LWT - Food Science and Technology, 43, 544-550.

Cekera, S., Agarb, G., Nardemirb, G., Anarc, M., Kizild, H. E., \& Alpsoye, L. (2012) Investigation of anti-oxidative and anti-genotoxic effects of Origanum vulgare L. essential oil on human lymphocytes in vitro. Journal of Essential Oils Bearing Plants, 15, 997-1005.

Chaudhry, N. M. A., Saeed, S., \& Tariq, P. (2007). Antibacterial effects of oregano (Origanum vulgare) against gram negative bacilli. Pakistan Journal of Botany, 39, 609-613.

Cleff, M. B., Meinerz, A. R., Sallis, E. S., Antunes, T. A., Mattei, A., Rodrigues, M. R., et al. (2008). Pre-clinic toxicity of the repeate-dose of Origanum vulgare L. (Origanum) essential oil in Wistar rats. Latin American Journal of Pharmacy, 27, 704-709.

Clifford, M. N., Johnston, K. L., Knight, S., \& Kuhnert, N. A. (2003). A hierarchical scheme for LC-MSn identification of chlorogenic acids. Journal of Agricultural and Food Chemistry, 51, 2900-2911.
Clifford, M. N., Knight, S., \& Kuhnert, N. A. (2005). Discriminating between the six isomers of dicaffeoylquinic acid by LC-MSn. Journal of Agricultural and Food Chemistry, 53, 3821-3832.

Economou, K. D., Oreopoulou, V., \& Thomopoulos, C. D. (1991). Antioxidant activity of some plant extracts of the family labiatae. Journal of American Oil Chemists Society, 68, 109-113.

EFSA (2010). Scientific opinion on the use of oregano and lemon balm extracts as a food. European Food Safety Authority Journal, 8, 1-19.

Ferreres, F., Silva, B. M., Andrade, P. B., Seabra, R. M., \& Ferreira, M. A. (2003) Approach to the study of C-glycosyl flavones by ion trap HPLC-PAD-ESI/MS/MS: Application to seeds of quince (Cydonia oblonga). Phytochemical Analysis, 14, 352-359.

Grevsen, K., Fretté, X. C., \& Christensen, L. P. (2009). Content and composition of volatile terpenes, flavonoids and phenolic acids in Greek oregano (Origanum vulgare L. ssp. hirtum) at different development stages during cultivation in cool temperate climate. European Journal of Horticulture Science, 74, 193-203.

Hossain, M. B., Rai, D. K., Brunton, N. P., Martin-Diana, A. B., \& Barry-Ryan, C. (2010). Characterization of phenolic composition in Lamiaceae spices by LC-ESI-MS/MS. Journal of Agricultural and Food Chemistry, 58, 10576-10581.

Kaurinovic, B., Popovic, M., Vlaisavljevic, S., \& Trivic, S. (2011). Antioxidant capacity of Ocimum basilicum L. and Origanum vulgare L. extracts. Molecules, 16, $7401-7414$.

Kosar, M., Dorman, H. J. D., \& Hiltunen, R. (2005). Effect of an acid treatment on the phytochemical and antioxidant characteristics of extracts from selected Lamiaceae species. Food Chemistry, 91, 525-533.

Koukoulitsa, C., Karioti, C., Bergonzi, M. C., Gpescitelli, G., Bari, L., \& Skaltsa, H. (2006). Polar constituents from the Aerial Parts of Origanum vulgare L. Ssp. hirtum growing wild in Greece. Journal of Agricultural and Food Chemistry, 54, 5388-5392.

Ličina, B. Z., Stefanović, O. D. Vasić, S. M., Radojević, I. D., Dekić, M. S., \& Čomić, L. R. (2013). Biological activities of the extracts from wild growing Origanum vulgare L.. Food Control, 33, 498-504.

Longe, J. L. (2005). The Gale encyclopedia of alternative medicine (2nd Editio. ed.). Thomson GALE.

Mabry, T. J., Markham, K. R., \& Thomas, M. B. (1970). The systematic identification of flavonoids. New York: Springer-Verlag Publication.

Miron, T. L., Plaza, M., Bahrim, G., Ibáñez, E., \& Herrero, M. (2011). Chemical composition of bioactive pressurized extracts of Romanian aromatic plants. Journal of Chromatography A, 1218, 4918-4927.

Nakatani, N., \& Kikuzaki, H. (1987). New antioxidative glucoside isolated from Oregano (Origanum vulgare L.). Agricultural and Biological Chemistry, 51, 2727-2732.

NCCLS/CLSI \& ANVISA. (2003). Padronização dos testes de sensibilidade a antimicrobianos por disco-difusão: Norma Aprovada - Oitava Edição.

Orhan, İ. E., Özçelík, B., Kartal, M., \& Kan, Y. (2012). Antimicrobial and antiviral effects of essential oils from selected Umbelliferae and Labiatae plants and individual essential oil components. Turkish Journal of Biology, 36, 239-246.

Özbek, T., Güllüce, M., Sahìn, F., Özkan, H., Sevsay, S., \& Bariş, Ö. (2008). Investigation of the antimutagenic potentials of the methanol extract of Origanum vulgare L. subsp. vulgare in the eastern Anatolia region of Turkey. Turkish Journal of Biology, 32, 271-276.

Quiroga, P. R., Grosso, N. R., Lante, A., Lomolino, G., Zygadlo, J. A., \& Nepote, V. (2013). Chemical composition, antioxidant activity and anti-lipase activity of Origanum vulgare and Lippia turbinata essential oils. International Journal of Food Science and Technology, 48, 642-649.

Rodríguez-Meizoso, I., Marin, F. R., Herrero, M., Señorans, F. J., Reglero, G., Cifuentes, A., et al. (2006). Subcritical water extraction of nutraceuticals with antioxidant activity from oregano. Chemical and functional characterization. Journal of Pharmaceutical and Biomedical Analysis, 41, 1560-1565.

Rosato, A., Vitali, C., Piarulli, M., Mazzotta, M., Argentieri, M. P., \& Mallamaci, R. (2009). In vitro synergic efficacy of the combination of Nystatin with the essential oils of Origanum vulgare and Pelargonium graveolens against some Candida species. Phytomedicine, 16, 972-975.

Ruan, M., Li, Y., Li, X., Luo, J., \& Kong, L. (2012). Qualitative and quantitative analysis of the major constituents in Chinese medicinal preparation Guan-Xin-Ning injection by HPLC-DAD-ESI-MS ${ }^{n}$. Journal of Pharmaceutical and Biomedical Analysis, 59, 184-189.

Saeed, S., \& Tariq, P. (2009). Antibacterial activity of oregano (Origanum vulgare Linn.) against gram positive bacteria. Pakistan Journal of Pharmaceutical Science, 22, 421-424.

Sahin, F., Güllüce, M., Daferera, D., Sökmen, A., Sökmen, M., Polissiou, M., et al. (2004). Biological activities of the essential oils and methanol extract of Origanum vulgare ssp. vulgare in the eastern Anatolia region of Turkey. Food Control, 15, 549-557.

Shen, D., Pan, M.-H., Wu, Q.-L., Park, C.-H., Juliani, H. R., Ho, C.-T., et al. (2010). LCMS Method for the simultaneous quantitation of the anti-inflammatory constituents in oregano (Origanum species). Journal of Agricultural and Food Chemistry, 58, 7119-7125.

Sivropoulou, A. (1996). Antimicrobial and cytotoxic activities of Origanum essential oils. Journal of Agricultural and Food Chemistry, 8561, 1202-1205.

Škerget, M., Kotnik, P., Hadolin, M., Hraš, A. R., Simonič, M., \& Knez, Ž. (2005). Phenols, proanthocyanidins, flavones and flavonols in some plant materials and their antioxidant activities. Food Chemistry, 89, 191-198.

Skoula, M., Grayer, R. J., Kite, G. C., \& Veitch, N. C. (2008). Exudate flavones and flavanones in Origanum species and their interspecific variation. Biochemical Systematics and Ecology, 36, 646-654. 
Spiridon, I., Bodirlau, R., \& Teaca, C.-A. (2011). Total phenolic content and antioxidant activity of plants used in traditional Romanian herbal medicine. Central European Journal of Biology, 6, 388-396.

Tisserand, R., \& Balacs, T. (1995). Essential oil safety: A guide for health care professionals. Churchill Livingstone (ed., p. 279).

Vale-Silva, L., Silva, M.-J., Oliveira, D., Gonçalves, M.-J., Cavaleiro, C., Salgueiro, L., et al. (2012). Correlation of the chemical composition of essential oils from Origanum vulgare subsp. virens with their in vitro activity against pathogenic yeasts and filamentous fungi. Journal of Medical Microbiology, 61, 252-260.
Vanaclocha, B., \& Cañigueral, S. (2003). Fitoterapia: Vademecum de Prescripción (4oEd. ed.), Barcelona.

Viuda-Martos, M., Ruiz-Navajas, Y., Fernandez-Lopez, J., \& Perez-Alvarez, J. A (2007). Antifungal activities of thyme, clove and oregano essential oils. Journal of Food Safety, 27, 91-101.

Zhang, X.-L., Guo, Y.-S., Wang, C.-H., Li, G.-Q., Xu, J.-J., Chung, H. Y., et al. (2014) Phenolic compounds from Origanum vulgare and their antioxidant and antiviral activities. Food Chemistry, 152, 300-306. 